\title{
GMR
}

\section{Polymorphisms in the vascular endothelial growth factor (VEGF) gene associated with asthma}

\author{
H.Y. Lu ${ }^{1}$, G.L. $\mathrm{Zhao}^{2}$ and M.F. Fu ${ }^{3}$ \\ 'Department of Respiration, Zoucheng People's Hospital, \\ Zoucheng, Shandong, China \\ ${ }^{2}$ Department of Internal and Emergency Medicine, \\ Jining No. 1 People's Hospital, Jining, Shandong, China \\ ${ }^{3}$ Department of Radiology, Zoucheng People's Hospital, \\ Zoucheng, Shandong, China \\ Corresponding author: G.L. Zhao \\ E-mail: liyan3000@yeah.net
}

Genet. Mol. Res. 15 (2): gmr. 15027880

Received October 22, 2015

Accepted December 28, 2015

Published May 6, 2016

DOI http://dx.doi.org/10.4238/gmr.15027880

\begin{abstract}
It has been proven that vascular endothelial growth factor (VEGF) is involved in airway restoration and the development of asthma. We sought to examine the relevance of $V E G F$ gene polymorphisms to asthma in the Chinese Han population. We extracted the whole genomic DNA from the peripheral blood of 471 participants, including 226 patients with asthma and 245 healthy controls. Seven single nucleotide polymorphisms (SNPs) of the VEGF gene were genotyped using the MassARRAY system. The data were then analyzed using HaploView 4.0 and SPSS 20.0 softwares. When comparing the asthma and control groups, significant differences were found in the genotype frequencies of rs3025020 and rs3025039 $(\mathrm{P}=0.001$ and $\mathrm{P}$ $=0.011$, respectively). The $\mathrm{T}$ alleles in $\mathrm{rs} 3025020$ and $\mathrm{rs} 3025039$ were significantly more prevalent in the asthma group than in controls $(\mathrm{P}=0.0003, \mathrm{P}=0.001$, respectively). Furthermore, a strong linkage
\end{abstract}


disequilibrium was observed in three blocks (block1-3). In block3, the asthma group had a significantly lower C-C haplotype frequency of haplotype $1(\mathrm{P}=0.000015)$, a higher T-C haplotype frequency of haplotype $2(\mathrm{P}=0.020)$, and a significantly higher $\mathrm{C}$-T haplotype frequency of haplotype $3(\mathrm{P}=0.001)$. The rs3025020 genotype showed no correlation with the clinical phenotype that may cause asthma. The $V E G F$ SNPs rs3025020 and rs3025039 may be associated with the development of asthma, indicating the role of VEGF in asthma.

Key words: Asthma; Vascular endothelial growth factor; Single nucleotide polymorphisms

\section{INTRODUCTION}

Asthma is a chronic inflammatory disease (Moffatt et al., 2010) that is mainly caused by airway obstruction and airway hyperresponsiveness (Holgate, 2002). Although the exact pathogeny of asthma is not clear, genetic and environmental factors jointly promote the occurrence of asthma, and its heritability may be as high as 79\% (Koppelman, 2006). In recent years, genome-wide-association studies (GWAS) have identified novel genome-wideassociated loci (Postma et al., 2011), but most of them have contributed little to understanding the cause of asthma. Therefore, it is necessary to acquire more reliable genetic locus data.

Vascular endothelial growth factor (VEGF) is one of the most effective angiogenic factors. It not only acts on endothelial cell proliferation (Yancopoulos et al., 2000) but also influences the proliferation of epithelial cells, fibroblasts, and even tumor cells. VEGF also plays a critical role in Th2-mediated inflammation and airway remodeling (Lee et al., 2004), which promote the occurrence of asthma. In asthmatic subjects, VEGF expression in the bronchoalveolar lavage fluid is notably higher than in healthy controls (Simcock et al., 2007), and VEGF expression in the sputum and plasma is associated with the severity of the asthma symptoms (Abdel-Rahman et al., 2006; Hossny et al., 2009). Therefore, we assume that VEGF is a strong candidate gene for asthma.

The human VEGF gene has the chromosomal locus 6p21.3 and contains a 14-kb coding region, which contains eight exons and seven introns. We chose seven single nucleotide polymorphism (SNPs) within the VEGF gene in this study: rs699947, rs1570360, rs2010963, rs3025006, rs3025010, rs3025020, and rs3025039. The SNPs rs699947, rs1570360, and rs2010963 are located in the promoter of the VEGF gene, and SNP rs3025039 is located in the 3'-untranslated region (UTR), where it may impact gene transcription (Krippl et al., 2003; Lambrechts et al., 2003). SNPs rs3025006 and rs3025010 are located in intron 5 of the VEGF gene, and SNP rs3025020 is located in intron 6, where it may affect the alternative splicing of the VEGF gene (Krippl et al., 2003; Lambrechts et al., 2003).

\section{MATERIAL AND METHODS}

\section{Subjects}

Recruitment of patients for this study was from our hospital. A total of 226 patients 
were enrolled as cases. This study was conducted after receiving ethical clearance from the Ethics Committee of our hospital. Each patient was subjected to examination by a doctor and fulfilled the criteria of the Global Initiative for Asthma guidelines. In addition, 245 agematched, healthy individuals without any symptoms of atopic, pulmonary disease, any other comorbid disease, or smoking habits were recruited as controls. Asthma patients with any other history of respiratory illness such as chronic obstructive pulmonary disease, tuberculosis, pneumonia, or bronchitis were excluded from the study. Apart from these, individuals with any other comorbid condition such as diabetes mellitus, hypertension, or pregnancy were also excluded as cases from the study.

All participants were Han Chinese from Shandong Province and were not genetically related. The study complied with the guidelines of our local Medical Ethics Committee, and all participants recruited to this study provided written informed consent.

\section{SNP genotyping}

Peripheral blood was drawn from a vein into a sterile tube containing ethylenediaminetetraacetic acid (EDTA). Plasma samples were stored at $-40^{\circ} \mathrm{C}$. Genomic DNA was extracted from frozen peripheral blood samples using a QIAmp Blood Mini Kit (Qiagen Inc., Valencia, CA, USA) according to the manufacturer instructions. DNA was stored at $-40^{\circ} \mathrm{C}$ for SNP analysis. Genotyping was performed for all SNPs using the MassARRAY platform (Sequenom, San Diego, CA, USA). Briefly, probes and primers were designed with the Assay Design software (Sequenom Inc.) and the genomic DNA samples were amplified by multiplex polymerase chain reaction (PCR). After a multiplex primer extension reaction was performed, terminator nucleotides were added to the diagnostic SNP site. Next, allele-specific extension products of different masses were analyzed in a matrix-assisted laser desorption/ionization time-of-flight (MALDI-TOF) SpectroReader mass spectrometer (Sequenom Inc.). Finally, the resulting spectra were processed with the Typer Analyzer software (Sequenom Inc.) and genotype data were generated for the samples. The final genotype call rate for each SNP was greater than $90 \%$ and the overall genotyping call rate was $99.7 \%$, ensuring the reliability of further statistical analysis.

\section{Statistical analysis}

All data were analyzed using the SPSS 20.0 software (SPSS Inc., Chicago, IL, USA). Allele and genotype frequencies for each individual polymorphism and Hardy-Weinberg equilibrium were evaluated by chi-square tests. The association between asthma and each polymorphism was analyzed using chi-square tests or Fisher exact tests. The odds ratio (OR) and $95 \%$ confidence interval $(95 \% \mathrm{CI})$ were used to assess the strength of the association between allele frequencies and CAD. Bonferroni corrections were used in multiple tests, and the Pvalue was divided by the total number of loci or haplotypes. Pairwise linkage disequilibrium (LD) statistics ( $\mathrm{D}^{\prime}$ and $\mathrm{r}^{2}$ ) and haplotype frequencies were computed using the HaploView 4.0 software to construct haplotype blocks. To ensure that the LD blocks most closely reflected the population level LD patterns, definitions of the blocks were based on the control samples alone. 


\section{RESULTS}

The seven SNPs in the $V E G F$ gene all conformed to the Hardy-Weinberg equilibrium. The genotype frequency of rs3025020 was significantly different between the asthma and control groups $(\mathrm{P}=0.001)$. The frequency of the $\mathrm{T}$ allele in the asthma group was significantly higher than in the control group $(\mathrm{P}=0.0003)$. Moreover, the distribution of the rs3025039 genotype was different between the asthma and control groups $(\mathrm{P}=0.011)$; however, statistical significance was not achieved after applying the Bonferroni correction $(\mathrm{P}<0.007)$. The $\mathrm{T}$ allele in the asthma group was present in a significantly higher proportion than in the control group ( $\mathrm{P}=0.001$; Tables 1 and 2$)$.

Table 1. Distribution of allele frequencies of vascular endothelial growth factor $(V E G F)$ gene polymorphisms.

\begin{tabular}{|c|c|c|c|c|c|c|c|}
\hline \multirow[t]{3}{*}{ SNP } & \multirow[t]{3}{*}{ Alleles } & \multicolumn{4}{|c|}{$\begin{array}{l}\text { Allele frequencies } \\
\end{array}$} & \multirow[t]{3}{*}{$P$ value } & \multirow[t]{3}{*}{ OR $(95 \% \mathrm{CI})$} \\
\hline & & \multicolumn{2}{|c|}{ Cases (226) } & \multicolumn{2}{|c|}{ Control (245) } & & \\
\hline & & $\mathrm{N}$ & $\%$ & $\mathrm{~N}$ & $\%$ & & \\
\hline \multirow[t]{2}{*}{ rs699947 } & A & 113 & 25.0 & 102 & 20.8 & 0.126 & $1.268(0.935-1.720)$ \\
\hline & $\mathrm{C}$ & 339 & 75.0 & 388 & 79.2 & & \\
\hline \multirow[t]{2}{*}{ rs 1570360} & $\mathrm{~A}$ & 114 & 25.2 & 102 & 20.8 & 0.108 & $1.283(0.946-1.739)$ \\
\hline & $\mathrm{G}$ & 338 & 74.8 & 388 & 79.2 & & \\
\hline \multirow[t]{2}{*}{ rs2010963 } & $\mathrm{C}$ & 188 & 41.6 & 200 & 40.8 & 0.809 & $1.033(0.796-1.339)$ \\
\hline & $\mathrm{G}$ & 264 & 58.4 & 290 & 59.2 & & \\
\hline \multirow[t]{2}{*}{ rs 3025006} & $\mathrm{C}$ & 220 & 48.7 & 223 & 45.5 & 0.331 & $1.135(0.879-1.467)$ \\
\hline & $\mathrm{T}$ & 232 & 51.3 & 267 & 54.5 & & \\
\hline \multirow[t]{2}{*}{ rs 3025010} & $\mathrm{C}$ & 96 & 21.2 & 97 & 19.8 & 0.584 & $1.093(0.796-1.499)$ \\
\hline & $\mathrm{T}$ & 356 & 78.8 & 393 & 80.2 & & \\
\hline \multirow[t]{2}{*}{ rs 3025020} & $\mathrm{C}$ & 233 & 51.5 & 310 & 63.3 & $0.0003^{*}$ & $0.618(0.476-0.801)$ \\
\hline & $\mathrm{T}$ & 219 & 48.5 & 180 & 36.7 & & \\
\hline \multirow[t]{2}{*}{ rs 3025039} & $\mathrm{C}$ & 332 & 73.5 & 402 & 82.0 & $0.001 *$ & $0.606(0.444-0.827)$ \\
\hline & $\mathrm{T}$ & 120 & 26.5 & 88 & 18.0 & & \\
\hline
\end{tabular}

$\mathrm{SNP}=$ single nucleotide polymorphism. $* \mathrm{P}$ values retained statistical significance after Bonferroni correction $(\mathrm{P}<0.007)$.

Table 2. Distribution of genotype frequencies of vascular endothelial growth factor $(V E G F)$ gene polymorphisms.

\begin{tabular}{|c|c|c|c|c|c|c|c|}
\hline \multirow[t]{3}{*}{ SNP } & \multirow[t]{3}{*}{ Genotype } & \multicolumn{4}{|c|}{ Genotype frequencies } & \multirow[t]{3}{*}{$\mathrm{P}^{a}$} & \multirow[t]{3}{*}{$\mathrm{P}^{b}$} \\
\hline & & \multicolumn{2}{|c|}{ Cases (226) } & \multicolumn{2}{|c|}{ Control (245) } & & \\
\hline & & $\mathrm{N}$ & $\%$ & $\mathrm{~N}$ & $\%$ & & \\
\hline \multirow[t]{3}{*}{ rs699947 } & AA & 14 & 6.2 & 12 & 4.9 & 0.592 & 0.291 \\
\hline & $\mathrm{AC}$ & 85 & 37.6 & 78 & 31.8 & & \\
\hline & $\mathrm{CC}$ & 127 & 56.2 & 155 & 63.3 & & \\
\hline \multirow[t]{3}{*}{ rs 1570360} & AA & 15 & 6.6 & 12 & 4.9 & 0.592 & 0.276 \\
\hline & AG & 84 & 37.2 & 78 & 31.8 & & \\
\hline & GG & 127 & 56.2 & 155 & 63.3 & & \\
\hline \multirow[t]{3}{*}{ rs2010963 } & $\mathrm{CC}$ & 34 & 15.0 & 33 & 13.5 & 0.039 & 0.878 \\
\hline & CG & 120 & 53.1 & 134 & 54.7 & & \\
\hline & GG & 72 & 31.9 & 78 & 31.8 & & \\
\hline \multirow[t]{3}{*}{ rs 3025006} & $\mathrm{CC}$ & 47 & 20.8 & 47 & 19.2 & 0.335 & 0.504 \\
\hline & CT & 126 & 55.8 & 129 & 52.7 & & \\
\hline & TT & 53 & 23.5 & 69 & 28.2 & & \\
\hline \multirow[t]{3}{*}{ rs3025010 } & $\mathrm{CC}$ & 9 & 4.0 & 10 & 4.1 & 0.872 & 0.775 \\
\hline & $\mathrm{CT}$ & 78 & 34.5 & 77 & 31.4 & & \\
\hline & TT & 139 & 61.5 & 158 & 64.5 & & \\
\hline \multirow[t]{3}{*}{ rs3025020 } & $\mathrm{CC}$ & 69 & 30.5 & 101 & 41.2 & 0.419 & $0.001 *$ \\
\hline & CT & 95 & 42.0 & 108 & 44.1 & & \\
\hline & TT & 62 & 27.4 & 36 & 14.7 & & \\
\hline \multirow[t]{3}{*}{ rs 3025039} & $\mathrm{CC}$ & 127 & 56.2 & 169 & 69.0 & 0.076 & 0.011 \\
\hline & $\mathrm{CT}$ & 78 & 34.5 & 64 & 26.1 & & \\
\hline & TT & 21 & 9.3 & 12 & 4.9 & & \\
\hline
\end{tabular}

$\mathrm{SNP}=$ single nucleotide polymorphism. $\mathrm{P}^{a}$ is the $\mathrm{P}$ value for the Hardy-Weinberg equilibrium test for healthy controls; $\mathrm{P}^{b}$ is the Pvalue of genotype frequency distribution differences between the asthma and control groups. *Pvalues retained statistical significance after Bonferroni correction $(\mathrm{P}<0.007)$. 
The haplotype structure and pairwise LD values $\left(\mathrm{r}^{2}\right)$ are shown in Figure 1. In block3, the asthma group had a significantly lower $\mathrm{C}-\mathrm{C}$ haplotype frequency of haplotype 1 ( $\mathrm{P}<$ $0.000015)$, a higher T-C haplotype frequency of haplotype $2(\mathrm{P}=0.020)$, and a significantly higher $\mathrm{C}$-T haplotype frequency of haplotype $3(\mathrm{P}=0.001)$ (Table 3$)$. We also found that the rs3025020 genotype showed no correlation with the clinical phenotype that may cause asthma (Table 4).

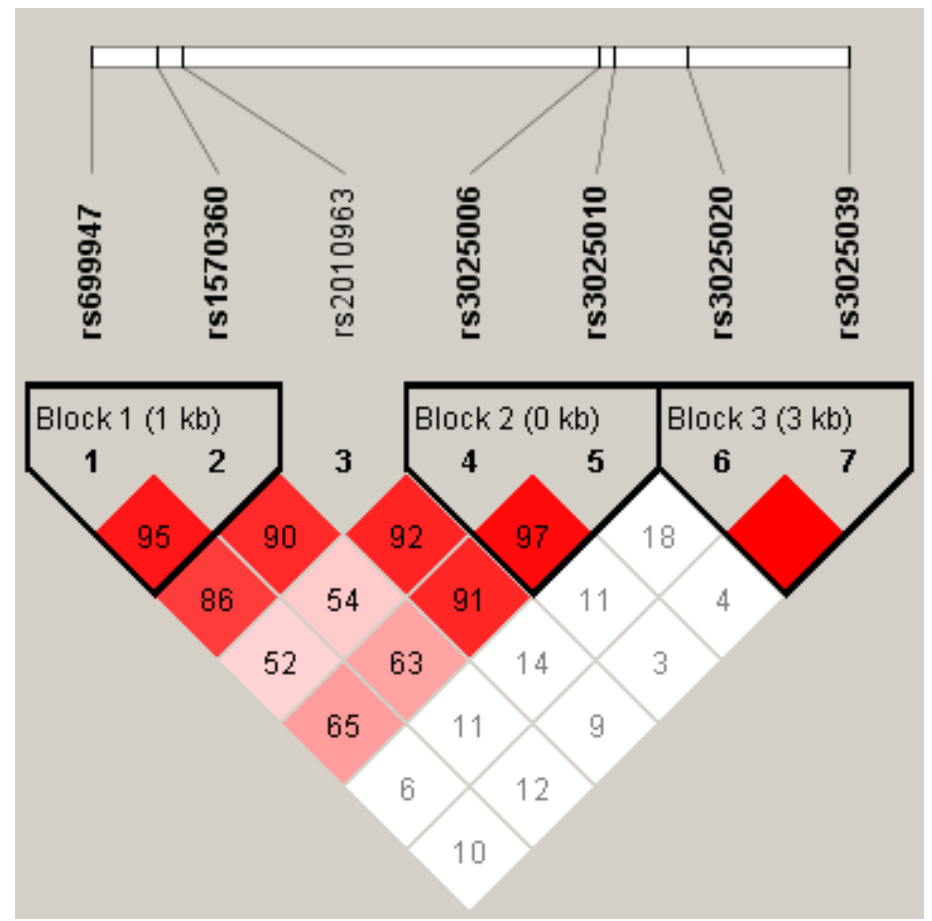

Figure 1. Linkage disequilibrium plot of the single nucleotide polymorphisms in the vascular endothelial growth factor $(V E G F)$ gene in controls.

Table 3. Frequencies of block1 haplotypes of the vascular endothelial growth factor $(V E G F)$ gene.

\begin{tabular}{|c|c|c|c|c|c|}
\hline \multicolumn{3}{|l|}{ Haplotype } & \multicolumn{2}{|c|}{ Gene counting (frequency, \%) } & \multirow[t]{2}{*}{$P$ value } \\
\hline ID & rs699947 & rs1570360 & Cases & Controls & \\
\hline \multicolumn{6}{|c|}{ Block1 rs699947-rs1570360 } \\
\hline HAP1 & $\mathrm{C}$ & $\mathrm{G}$ & 160 & 192 & 0.059 \\
\hline HAP2 & A & $\mathrm{A}$ & 48 & 49 & 0.740 \\
\hline \multicolumn{6}{|c|}{ Block2 rs3025006-rs3025010 } \\
\hline HAP1 & $\mathrm{T}$ & $\mathrm{T}$ & 116 & 133 & 0.521 \\
\hline HAP2 & $\mathrm{C}$ & $\mathrm{T}$ & 62 & 64 & 0.748 \\
\hline HAP3 & $\mathrm{C}$ & $\mathrm{C}$ & 48 & 48 & 0.066 \\
\hline \multicolumn{6}{|c|}{ Block3 rs3025020-rs3025039 } \\
\hline HAP1 & $\mathrm{C}$ & $\mathrm{C}$ & 59 & 111 & $0.000015^{*}$ \\
\hline HAP2 & $\mathrm{T}$ & $\mathrm{C}$ & 107 & 90 & 0.020 \\
\hline HAP3 & $\mathrm{C}$ & $\mathrm{T}$ & 58 & 44 & $0.001 *$ \\
\hline
\end{tabular}

*P values retained statistical significance after Bonferroni correction $(\mathrm{P}<0.017)$. 
Table 4. Dependent characteristics by genotype of vascular endothelial growth factor (VEGF) gene rs3025020 polymorphism.

\begin{tabular}{|c|c|c|c|c|}
\hline Variables & $\mathrm{CC}$ & СT & TT & $P$ value \\
\hline \multicolumn{4}{|c|}{ Allergic parents } & 0.266 \\
\hline Yes & 32 & 53 & 27 & \\
\hline No & 37 & 42 & 35 & \\
\hline \multicolumn{4}{|c|}{ Smoking habit } & 0.261 \\
\hline Yes & 28 & 46 & 34 & \\
\hline No & 41 & 49 & 28 & \\
\hline \multicolumn{4}{|c|}{ Cesarean section } & 0.103 \\
\hline Yes & 15 & 23 & 23 & \\
\hline No & 54 & 72 & 39 & \\
\hline \multicolumn{4}{|c|}{ Breast feeding } & 0.320 \\
\hline Yes & 24 & 40 & 19 & \\
\hline No & 45 & 55 & 43 & \\
\hline \multicolumn{4}{|c|}{ Hairy pet at home } & 0.230 \\
\hline Yes & 20 & 30 & 12 & \\
\hline No & 49 & 65 & 50 & \\
\hline \multicolumn{4}{|c|}{ Occupational allergens } & 0.568 \\
\hline Yes & 8 & 11 & 12 & \\
\hline No & 61 & 84 & 60 & \\
\hline Age (years) & & & & 0.071 \\
\hline$\sim 18$ & 18 & 29 & 12 & \\
\hline $19-40$ & 10 & 16 & 20 & \\
\hline $41 \sim$ & 41 & 50 & 30 & \\
\hline
\end{tabular}

\section{DISCUSSION}

The VEGF SNP rs3025020 is located in intron 6 of the VEGF gene and has been reported to be associated with hypertensive cerebellar hemorrhage $(\mathrm{HCH})$ and rehabilitative treatment; individuals who carry the T allele are more susceptible to $\mathrm{HCH}$ (He et al., 2015). The rs3025020 polymorphism may increase recurrent spontaneous abortion susceptibility (Almawi et al., 2013). Furthermore, individuals with the rs3025020 T/T genotype have higher VEGF serum levels compared with healthy individuals (Al-Habboubi et al., 2011). In this study, we found that the $V E G F$ gene rs3025020 polymorphism was associated with asthma, and the frequency of the $\mathrm{T}$ allele in the asthma group was significantly higher than in the control group. These results suggest that the VEGF rs3025020 polymorphism plays an important role in cell proliferation and in inappropriate VEGF-induced angiogenesis, which is implicated in asthma. For example, asthma patients have a higher percentage of vessels in the bronchial mucosa than healthy individuals (Feltis et al., 2006). However, whether the VEGF rs3025020 polymorphism is associated with asthma has not yet been determined. Our research demonstrates a definite link between rs3025020 and asthma in the Chinese Han population.

The VEGF rs3025039 SNP is located in the 3'-UTR of the VEGF gene. We found 
that the $\mathrm{T}$ allele in the asthma group was present in a significantly higher proportion than in the control group. The VEGF rs3025039 SNP is not only associated with asthma (Lachheb et al., 2008); like the $V E G F$ rs3025020 polymorphism, rs3025039 is also associated with other diseases, for example, bisphosphonate-related osteonecrosis of the jaw (Choi et al., 2015) and ovarian cancers (Janardhan et al., 2015). Compared with healthy controls, the frequency of the T allele of rs3025039 is significantly higher in patients with $\mathrm{HCH}$ (He et al., 2015). This may be because the rs3025020-rs3025039 (block3) has a strong LD. In block3, the asthma group has a significantly lower C-C haplotype frequency and higher T-C and C-T haplotype frequencies. Of these, the T-C and C-T haplotypes are linked with higher VEGF expression (Al-Habboubi et al., 2011). Therefore, we suspect that rs3025020-rs3025039 is associated with asthma.

In the promoter region of the $V E G F$ gene, we found no significant difference between the asthma and control groups, although rs699947 has been reported to be associated with VEGF plasma level, pre-school lung function, and lung cancer risk (Kreiner-Møller et al., 2013; Fan et al., 2015), and the G allele of rs2010963 has been reported to be associated with asthma (Lachheb et al., 2008). These differences probably result from disparities in the sample sizes, populations, and clinical phenotypes. Sample size has a great influence on the statistical power of polymorphism research. In general, larger sample sizes are associated with more reliable statistical results (Hong and Park, 2012). When the population or race is different, the genetic background may also be different. For example, the $\mathrm{G}$ allele of rs 2010963 has been reported to be associated with asthma in Tunisian children.

To summarize, our research will help scientists to better understand the potential pathogenesis of asthma. The rs3025020 and rs3025039 polymorphisms of VEGFmay play an important role in asthma. The details regarding the role of these SNPs in asthma have yet to be determined.

\section{REFERENCES}

Abdel-Rahman AM, el-Sahrigy SA and Bakr SI (2006). A comparative study of two angiogenic factors: vascular endothelial growth factor and angiogenin in induced sputum from asthmatic children in acute attack. Chest 129: 266271. http://dx.doi.org/10.1378/chest.129.2.266

Al-Habboubi HH, Sater MS, Almawi AW, Al-Khateeb GM, et al. (2011). Contribution of VEGF polymorphisms to variation in VEGF serum levels in a healthy population. Eur. Cytokine Netw. 22: 154-158.

Almawi WY, Saldanha FL, Mahmood NA, Al-ZamanI, et al. (2013). Relationship between VEGFA polymorphisms and serum VEGF protein levels and recurrent spontaneous miscarriage. Hum. Reprod. 28: 2628-2635. http://dx.doi. org/10.1093/humrep/det308

Choi H, Lee JH, Kim HJ, Park W, et al. (2015). Genetic association between VEGF polymorphisms and BRONJ in the Korean population. Oral Dis. 21: 866-871. http://dx.doi.org/10.1111/odi.12355

Fan J, Zhang W, Lei C, Qiao B, et al. (2015). Vascular endothelial growth factor polymorphisms and lung cancer risk. Int. J. Clin. Exp. Med. 8: 6406-6411.

Feltis BN, Wignarajah D, Zheng L, Ward C, et al. (2006). Increased vascular endothelial growth factor and receptors: relationship to angiogenesis in asthma. Am. J. Respir. Crit. Care Med. 173: 1201-1207. http://dx.doi.org/10.1164/ $\underline{\mathrm{rccm} .200507-1105 \mathrm{OC}}$

He QS, Yang LF, Wang WB, Yuan B, et al. (2015). Vascular endothelial growth factor gene is associated with hypertensive cerebellar hemorrhage and rehabilitative treatment. Genet. Mol. Res. 14: 9849-9857. http://dx.doi.org/10.4238/2015. August.19.18

Holgate ST (2002). Airway inflammation and remodeling in asthma: current concepts. Mol. Biotechnol. 22: 179-189. http://dx.doi.org/10.1385/MB:22:2:179

Hong EP and Park JW (2012). Sample size and statistical power calculation in genetic association studies. Genomics 
Inform.10: 117-122. http://dx.doi.org/10.5808/GI.2012.10.2.117

Hossny E, El-Awady H, Bakr S and Labib A (2009). Vascular endothelial growth factor overexpression in induced sputum of children with bronchial asthma. Pediatr. Allergy Immunol. 20: 89-96. http://dx.doi.org/10.1111/j.13993038.2008.00730.x

Janardhan B, Vaderhobli S, Bhagat R, Chennagiri Srinivasamurthy P, et al. (2015). Investigating impact of vascular endothelial growth factor polymorphisms in epithelial ovarian cancers: a study in the Indian population. PLoS One 10: e0131190. http://dx.doi.org/10.1371/journal.pone.0131190

Koppelman GH (2006). Gene by environment interaction in asthma. Curr. Allergy Asthma Rep. 6: 103-111. http://dx.doi. org/10.1007/s11882-006-0047-y

Kreiner-Møller E, Chawes BL, Vissing NH, Koppelman GH, et al. (2013). VEGFA variants are associated with pre-school lung function, but not neonatal lung function. Clin. Exp. Allergy 43: 1236-1245. http://dx.doi.org/10.1111/cea.12188

Krippl P, Langsenlehner U, Renner W, Yazdani-Biuki B, et al. (2003). A common 936 C/T gene polymorphism of vascular endothelial growth factor is associated with decreased breast cancer risk.Int. J. Cancer106: 468-471. http://dx.doi. org/10.1002/ijc. 11238

Lachheb J, Chelbi H, Ben Dhifallah I, Ammar J, et al. (2008). Association of vascular endothelial growth factor polymorphisms with asthma in Tunisian children. Gene Regul. Syst. Biol. 2: 89-96.

Lambrechts D, StorkebaumE, MorimotoM, Del-FaveroJ, et al.(2003). VEGF is a modifier of amyotrophic lateral sclerosis in mice and humans and protects motoneurons against ischemic death.Nat. Genet.34: 383-394. http://dx.doi. org/10.1038/ng1211

Lee CG, Link H, Baluk P, Homer RJ, et al. (2004). Vascular endothelial growth factor (VEGF) induces remodeling and enhances TH2-mediated sensitization and inflammation in the lung. Nat. Med. 10: 1095-1103. http://dx.doi. org $/ 10.1038 / \mathrm{nm} 1105$

Moffatt MF, GutI G, Demenais F, Strachan DP, et al. (2010). A large-scale, consortium-based genomewide association study of asthma. N. Engl. J. Med. 363: 1211-1221. http://dx.doi.org/10.1056/NEJMoa0906312

Postma DS, Kerkhof M, Boezen HM and Koppelman GH (2011). Asthma and chronic obstructive pulmonary disease: common genes, common environments? Am. J. Respir. Crit. Care Med.183: 1588-1594. http://dx.doi.org/10.1164/ $\underline{\text { rccm.201011-1796PP }}$

Simcock DE, Kanabar V, Clarke GW, O’Connor BJ, et al. (2007). Proangiogenic activity in bronchoalveolar lavage fluid from patients with asthma. Am. J. Respir. Crit. Care Med. 176: 146-153. http://dx.doi.org/10.1164/rccm.200701$\underline{0420 \mathrm{C}}$

Yancopoulos GD, Davis S, Gale NW, Rudge JS, et al. (2000). Vascular-specific growth factors and blood vessel formation. Nature 407: 242-248. http://dx.doi.org/10.1038/35025215 